http://dx.doi.org/10.26694/pensando.v10i21.8957

\title{
REFLEXÕES SOBRE A CONCEPÇÃO MAQUIAVELIANA DE LIBERDADE, SUA CORRUPÇÃO E SUA RESTAURAÇÃO*
}

\author{
Thoughts on the machiavellian conception of freedom, \\ its corruption and its restoration
}

José Luiz Ames
UNIOESTE

Resumo: O que Maquiavel entende por liberdade, o que pode levar à sua degradação e como será possível restaurá-la? Esta é a pergunta que nos guiará nesta reflexão. Nossa hipótese é de que a liberdade, para Maquiavel, é resultado do movimento de resistência ativa do povo ao desejo de dominação dos grandes; ela é, pois, fruto da ação - da luta política - no espaço público e só existirá neste espaço enquanto persistir a resistência à dominação. Este desejo do povo de não ser dominado pode degradar-se por dois movimentos opostos, mas que produz o mesmo efeito. Por um lado, quando o povo passa a ser movido pelo excesso do desejo de liberdade e passa a lutar por ambição, o que se mostra quando dá vazão ao desejo de controle pleno dos mecanismos de poder e passa a desejar como os grandes. Por outro lado, quando o povo revela falta do desejo de liberdade, o que se mostra na ausência de resistência à dominação e se submete voluntariamente ao jugo. Finalmente, como é possível a um povo que perdeu a liberdade de recobrá-la? Nos capítulos XVI a XVIII Livro I dos Discursos Maquiavel examina três diferentes situaçoes: como instaurar uma vida livre quando um povo, acostumado ao jugo de um príncipe, se liberta (capítulo XVI); como tornar livre uma cidade corrompida quando morre seu príncipe (capítulo XVII); como proceder para retomar à liberdade uma cidade tomada inteiramente pela corrupção (capítulo XVIII).

Palavras chave: Maquiavel, liberdade política, corrupção política, reforma política

\begin{abstract}
What does Machiavelli mean by freedom, what can lead to its degradation and how can it be restored? This is the question that will guide us in this reflection. Our hypothesis is that freedom, for Machiavelli, is the result of the active resistance movement of the people to the desire for domination of the great; it is, therefore, the result of the action - of the political struggle - in the public space and and only exist in this space while persisting resistance to domination. This desire of the people not to be dominated can be degraded by two opposing movements, but which produces the same effect. On the one hand, when the people start to be moved by the excessive disire for freedom and starts to fight for ambition, which is shown when it gives vent to the desire of full control of the mechanisms of power and happens to wish like the big ones. On the other hand, when the people reveal a lack of desire for freedom, which is shown in the absence of resistance to domination and voluntarily submits to the yoke. Finally, how is it possible for a people who have lost the freedom to recover it? In chapters XVI to XVIII Book I of the Discourses Machiavelli examines three different situations: how to establish a free life when a people, accustomed to the yoke of a prince, is freed (chapter XVI); how to free a corrupted city when its prince dies (chapter XVII); how to return to freedom a city taken entirely by corruption (chapter XVIII).
\end{abstract}

Keyword: Machiavelli, political freedom, political corruption, political reform.

\footnotetext{
"Este texto é fruto de um trabalho de pesquisa desenvolvido com o apoio do Conselho Nacionall de Desenvolvimento Cientifíico e Tecnológico (CNPq), Brasil.
} 


\section{A concepção maquiaveliana de liberdade}

Maquiavel escreve em O Príncipe (IX:2) que "em toda cidade se encontram estes dois diferentes humores [grandes e povo], os quais nascem disso: que o povo deseja não ser comandado nem oprimido pelos grandes e os grandes desejam comandar e oprimir o povo"1. Esta ideia será reafirmada em duas obras políticas posteriores: Discursos sobre a primeira década de Tito Lívio (I, 4:5) e Histórias florentinas (II,12). Grandes e povo se confrontam, pois, numa relação assimétrica. A assimetria desta relação resulta da diferença de posição dos atores em confronto: de uma parte o desejo de "comandar" do lado dos grandes e de outra parte o desejo de "não ser comandado" do lado do povo. Para Frosini (2010, p. 104), esta dialética conflitual configura uma colocação espacial na qual os grandes ocupam o lugar "alto" e o povo a posição "baixa" da relação. Diante de semelhante configuração de desejos, fica evidente a impossibilidade de haver uma composição, um acordo, constituindo-se, segundo Lefort, em "uma oposição constitutiva do político"?

Uma relação na qual uma parte quer comandar e oprimir e a outra recusa qualquer comando e opressão obviamente será fonte de tumultos. Maquiavel, contra a opinião corrente de seu tempo, atribui aos tumultos resultantes desta dialética conflitual a origem da grandeza romana, a começar pela criação da estrutura mista da constituição de Roma. Segundo Maquiavel, a inclusão do povo no governo republicano não foi resultado de uma ideia abstrata de constituição segundo a qual esta deveria comportar a participação de todas as partes da cidade para alcançar sua "perfeição", como ocorreu na constituição espartana inventada por Licurgo, mas se deveu "à desunião que havia entre plebe e senado" (Discursos I, 2:30) ${ }^{3}$. Maquiavel descreve do seguinte modo a origem da "mistura" da constituição romana: uma vez depostos os reis, foram criados dois órgãos cônsules e senado - ambos representados por membros da nobreza, de sorte que este grupo social detinha o monopólio do governo da cidade; devido à "insolência" deles, "o povo sublevou-se contra a nobreza romana" obrigando-a "a conceder ao povo a sua parte". Foi, portanto, um ato de força, uma "sublevação", ou um "levante popular" (si levò il popolo, escreve Maquiavel) contra a nobreza que tornou possível evitar as consequências destrutivas ao vivere libero e civile que derivariam do monopólio do poder pelos ottimati. O resultado da insubordinação do povo foi a criação de uma instituição representadora de seus interesses: os Tribunos do Povo. Com sua criação, escreve Maquiavel, "tornou-se mais estável o estado daquela república, visto que as três formas de governo tinham a sua parte" 5 .

No entendimento de Raimondi, este processo mostra que, para Maquiavel, "a liberdade se identifica com o stato popolare, ou seja, com a forma republicana, não porque nela governa unicamente o povo, e sim porque somente numa república é possível para o povo regular por si mesmo a relação com os grandes"6. Dessa maneira, ser livre, para Maquiavel, é possível unicamente porque, como escreve em Discursos, "o povo, [...] não [...] podendo ele ocupar [a liberdade], não permitirá que outros a ocupem" Se a república romana "tornou-se mais estável" com a criação do Tribunato foi porque o espaço público integrou nele todas as forças políticas. Com isso, o embate entre grandes e povo pode dar-se como enfrentamento "político", isto é, dentro das ordenações publicamente estabelecidas e não como luta privada, necessariamente sectária e

\footnotetext{
${ }^{1}$ MAQUIAVEL, N. O Príncipe (edição bilíngue). Tradução e notas de José Antônio Martins. São Paulo: Hedra, 2009, cap. IX, parágrafo 2, p. 109. Cotejaremos a tradução com o texto original da referida edição e introduziremos modificações pontuais sempre que as considerarmos necessárias.

${ }^{2}$ LEFORT, C. Le Travail de l'ouvre Machiavel Paris: Éditions Gallimard, 1972, p. 382

${ }^{3}$ MACHIAVELLI, N. Discorsi sopra la prima Deca di Tito Livio. Introdução de Gennaro Sasso; preâmbulo e notas de Giorgio Inglese. Milano: Rizzoli Editore, 2000, Livro I, Cap. 2, parágrafo 30, p. 68

${ }^{4}$ MACHIAVELLI, N. Discorsi sopra la prima Deca di Tito Livio. Op. Cit. Livro I, Cap. 2, parágrafo 34, p. 69.

${ }^{5}$ MACHIIVELLI, N. Discorsi sopra la prima Deca di Tito Livio. Op. Cit. Livro I, Cap. 2, parágrafo 34, p. 69.

${ }^{6}$ RATMONDI, F. L'ordinamento della libertà: Machiavelli e Firenze. Verona: Ombre Corte, 2013, p. 53.

${ }_{7}$ MACHIAVELLI, N. Discorsi sopra la prima Deca di Tito Livio. Op. Cit. Livro I, Cap. 5, parágrafo 8, p. 73.
} 
divisionista.

No capítulo IV Maquiavel radicaliza o papel dos tumultos como produtor de liberdade política ao atribuir a eles o mérito de todas as medidas jurídico-políticas por meio das quais a república romana promoveu e assegurou a liberdade. Podemos ler isso nesta passagem:

Digo que aqueles que condenam os tumultos entre os nobres e a plebe parece que censuram aquelas coisas que foram a causa primeira que manteve livre Roma, e que consideram mais os rumores e grita que de tais tumultos nasciam do que os bons efeitos que geravam; e que não consideram que em toda república existem dois humores diferentes, o do povo e o dos grandes e que todas as leis que se fazem a favor da liberdade nascem da desunião entre eles (grifos nossos).

Ao sustentar que os tumultos em Roma "raras vezes davam origem ao exílio, e raríssimas a sangue", Maquiavel procura ressaltar o caráter político deles, de modo que não se justifica a crítica condenatória expressa pela "opinião de muitos" de que teriam feito de Roma "uma república tumultuosa". Em vez de olhar para a violência que, por vezes, caracterizou os tumultos, Maquiavel procura dirigir o foco da atenção para os efeitos positivos sobre a liberdade republicana. $\mathbb{E}$ dos tumultos que nasceram "todas as leis que se fazem a favor da liberdade", de modo que Maquiavel os considera como a primeira, senão a única, fonte da qual se originaram todas as estruturas institucionais que cooperaram positivamente para a liberdade da cidade, constituindo-se, assim, na verdadeira causa de todo bem político. A liberdade de uma cidade garante a possibilidade do confronto entre os cidadãos enquadrando-o dentro de ordenações, cuja finalidade não é a de garantir o êxito, e sim a de evitar a corrupção. A ausência de liberdade, pelo contrário, abre espaço aos conflitos desregrados e às divisões que comprometem o bem comum. É por esse motivo que não cabe a crítica generalizada aos tumultos, em cuja origem está o povo em sua luta política contra a pretensão dos grandes de comandá-lo e oprimi-lo:

não se pode de modo algum com razão chamar desordenada uma república na qual existem tantos exemplos de virtu, porque os bons exemplos nascem da boa educação, a boa educação das boas leis e as boas leis daqueles tumultos que muitos irrefletidamente condenam9; porque, quem examinar bem o fim deles não encontrará que tenham dado origem a algum exílio ou violência em prejuízo ao bem comum, mas a leis e ordenações em benefício da liberdade pública (grifos nossos $)^{10}$ 。

Ao afirmar que os tumultos estão na origem das "leis e ordenações em benefício da liberdade pública" Maquiavel dá a entender que não seria possível manter a liberdade republicana se não existisse o confronto entre grandes e povo. É como se entendesse que, se não existisse quem quer não ser comandado e de outro quem quer comandar, também não existiria o espaço político do vivere libero, mas tão somente luta por bens e interesses privados. Sem a dinâmica dos tumultos entre os humores de grandes e povo não existiria vida política, pura e simplesmente. É o que leva Illuminati e Rispoli a sustentarem que "os tumultos modificam, modelam [e] reinventam desde o princípio as formas instituídas"11. É evidente A novidade radical desta compreensão em relação ao

\footnotetext{
${ }^{8}$ MACHAVELLI, N. Discorsi sopra la prima Deca di Tito Livio. Op. Cit. Livro I, Cap. 4, parágrafo 5, p. 71. 9 Maquiavel aponta para uma recursividade entre leis e bons costumes. "Tomadas isoladamente, são incapazes de frear a corrupção", observa Raimondi (2013, p. 14), e continua: "note-se a assimetria: os costumes devem ser bons para que as leis sejam respeitadas; por sua vez, as leis se tomam boas apenas se promovem os bons costumes". A pura coação extema da força legal é incapaz de produzir a virtù. Em outras palavras, para Maquiavel não há como a lei ser capaz de "obrigar o homem a ser livre", como pensa Skinner. O único modo de produzir e conservar a virt̀̀ é expor o povo a uma situação de perigo e insegurança, relativos, mas constantes; em outras palavras, é a exposição constante à necessidade que gera a virtù.

${ }^{10}$ MACHIAVELLI, N. Discorsi sopra la prima Deca di Tito Livio. Op. Cit. Livro I, Cap. 4, parágrafo 7, p. 71.

${ }^{11}$ ILLUMTNATI, Augusto e RISPOLI, Tania. Tumulti. Scene dal nuovo disordine planetario. Roma: Derive Approdi, 2011, p. 34 .
} 
hhumanismo renascentista e toda a tradição medieval da concordia ordinis. Os tumultos são, pois, a exposição constante da sociedade política à situação de risco, o que Maquiavel designa também por exposição à necessidade. Resulta disso que liberdade, para Maquiavel, não é o exercício autônomo da própria vontade individual (como será entendido na modemidade posterior, notadamente a partir de Hobbes), mas a capacidade de enfrentar a constrição, isto é, os perigos e a insegurança provocados pelos tumultos. Consequentemente, a liberdade não é um dado, nem natural nem político, mas sempre o resultado de uma forma de agir em um contexto determinado. Como aponta Dejardin, a concepção de liberdade maquiaveliana como ordenamento implica em que ela não é "algo natural nem sobrenatural, mas artificial", que nasce apenas com e dentro da "cidade"12. Para dizer em outras palavras: a liberdade não é uma estrutura antropológica natural (como a entenderăo os contratualistas na modernidade posterior quando a definirão como um "direito natural"), e sim um modo de existir público resultante da ação política dos atores que se confrontam em torno da afirmação de seus interesses. Mais precisamente: para Maquiavel, não a liberdade em sí, mas somente o desejo de liberdade, que aparece como resistência à dominação e comando dos grandes, constitui a condição "natural" dos homens. Em suma, ser livre significa, portanto, e por mais paradoxal que isso pareça, lutar pela liberdade. Por esse motivo, para Maquiavel a liberdade é pública (e não uma forma da consciência subjetiva individual) assegurada por leis e ordenações que têm em vista o bem comum. Trata-se, como podemos perceber, de uma concepção eminentemente política de liberdade. Para Barberis, trata-se de "uma concepção pré-liberal da liberdade pela qual as leis defendem o cidadão não do Estado, mas de qualquer um que [...] possa subtrair-lhe a vida, os bens e a honra"13.

Maquiavel tem claro que os tumultos são capazes de fazer surgir leis e instituições apenas na medida em que tensionam a coletividade política até o seu limite. É precisamente a isso que a atuação do povo leva a comunidade: sua ação parece instituir o caos, pois contesta a legitimidade das instituições que regulam a vida política. Maquiavel mostra que, sem produzir na comunidade política a sensação do risco de dissolução, os grandes não cedem em seu desejo de "comandar e oprimir". Para dizê-lo de modo bem radical com Dejardin, "uma cidade forte é aquela que se encontra em insurreição permanente" 1 . A ordem, portanto, brota da desordem: as "boas leis", na visão Maquiavel, nascem dos "tumultos que muitos condenam sem pensar"15. Sem um quadro de extrema "desordem" nenhuma "ordem" nova é capaz de surgir. Eis porque "os tumultos não podem ser solucionados de uma vez por todas tampouco pela forma da perfeita da constituição mista"16.

O antagonismo entre grandes e povo aparece como equilíbrio conflitual sempre exposto ao desequilíbrio ou, como prefere Raimondi, um "equilíbrio desequilibrado, assimétrico, instável e sempre à beira do caos [...] no qual a liberdade e a segurança são garantidas unicamente na exposição arriscada de si mesmo nos tumultos"17. O controle para que nenhuma das diferentes partes que compõem a cidade se imponha de modo absoluto sobre as demais não é exercido exteriormente pela estruttura constitucional da república, e sim brota do jogo de relações de força.

Isso nos permite compreender que numa cidade em que, por hipótese, os grandes dominassem plenamente, a liberdade ficaria negada também àqueles que dominam, pois não se é livre porque todos os demais são servos ou porque se pode fazer o que se deseja. A liberdade está ligada ao fato de que ninguém prevalece sobre os outros, isto é, que todos observam as leis e os bons costumes que as geram e que, ao

12 DEJARDIN, Bertrand. Terreur et comption. Essai sur l'incivilité chez Machiavel. Paris: L'Harmattan, 2004, p. 67.

${ }^{13}$ BARBERIS, M. Libertà Bologna: II Mulino, 1999, p. 69.

${ }^{14}$ DEJARDIN, Bertrand. Terrevr et compion, Op. cit., p. 116-117.

${ }^{15}$ MACHIAVELL, N. Discorsi sopra Ia prima Deca di Tito Livio. Op. Cit. Livro I, Cap. 4, parágrafo 7, p. 71.

${ }^{16}$ GEUNA, Marco. Machiavelli e il ruolo dei conflitti nella vita politica. In VV.AA. Conflitti (a cura di Arienzo, A. Caruso, D.). Napoli: Dante\&Descartes, 2005, p. 22.

${ }_{17}$ RATMONDI, F. L'ordinamento della liberta Op. cit., p. 55. 
mesmo tempo, são o efeito deles.

Muito embora Maquiavel insista em que o desejo de ser livre se exprime na disposição à luta, nem todas as lutas são iguais. Com efeito, como distingue Raimondi, "existe uma profunda assimetria entre os tumulti do povo e as discordie dos grandes"18. Assim, enquanto "os tumultos exprimem a vontade de não ser dominado e, portanto, de manter vazio o espaço da liberdade no qual se desenrola a luta política pelo bem comum, [...] as discórdias expressam a vontade de dominação, a disposição de fechar o espaço de liberdade, ou seja, da política"19. Assim, o tumulto é produtor de um vivere libero et civile somente enquanto permanece a tensão entre as forças em confronto; enquanto se produzem leis que não tenham em vista nem a vantagem de uma parte nem de outra, e sim a liberdade da cidade; enquanto, enfim, não houver a submissão definitiva de uma parte a outra. Significa dizer: o espaço da liberdade política se encontra na resistência recíproca, o que pressupõe a existência de um ordenamento político no qual exista a mistura das forças que compõem a cidade. Conclui-se dali que a liberdade jamais está dada, mas acontece sempre apenas enquanto. O desejo popular, que aparece como resistência ativa, é negativo (no sentido de definir-se por um não - de não dominação) em sua oposição ao desejo positivo dos grandes (de dominação).

Contudo, muito embora o desejo do povo seja o de "não ser dominado", ele é, sustenta Frosini, "ontologicamente idêntico ao das outras partes, grandes e príncipes"20. Na interpretação de Frosini, Maquiavel deixa, pois, patente de que não existe uma relação essencial entre povo e liberdade, como se o único desejo que o anima fosse o de viver livre, e que seria incapaz de exercer a dominação sobre a parte adversária. Apesar de os humores serem, como diz Frosini, "ontologicamente idênticos", não podem ser, porém, completamente equiparados, porque se confrontam em posiç̧ões diferentes do espaço político das relações de poder: ou seja, de "comandar" (os grandes) e de "não ser comandado" (o povo). Assim, não é um acaso que o desejo de liberdade esteja ligado à posição ocupada pelo povo, e jamais àquela ocupada pelos grandes. Em outras palavras, a ligação do povo com a liberdade não é casual, como se o povo estivesse acidentalmente ligado à liberdade, e que isso poderia igualmente acontecer, eventualmente, também com os grandes: estes, pela posição de comando e dominação que exercem, estão animados pelo desejo de oprimir e, consequentemente, simplesmente não têm como ligar sua existência política à liberdade. O desejo dos grandes é sempre parcial por estar ligado a âmbitos particulares da vida política (como cargos, bens e honras); por ser desejo por bens determinados, pressupõe a exclusão da outra parte (o povo). O desejo do povo, pelo contrário, por estar na posição de quem sofre o comando e a dominação, necessariamente resiste à opressão exercida pelos grandes, ou seja, está movido pelo desejo de liberdade.

Assim, o desejo do povo, mesmo sendo desejo de uma parte, é universal, pois implica, para sua realização, na inclusão de todas as partes - grandes e povo. Significa dizer: a liberdade desejada pelo povo, muito embora seja o desejo de uma parte, não produz liberdade unicamente para o povo, mas ao conjunto da coletividade política. Como dissemos antes, não se é livre porque os demais estão sulbmetidos à obediência, e sim, a liberdade está ligada à situação na qual ninguém pode prevalecer sobre os outros. Dessa maneira, pode-se dizer que o povo, ao reivindicar a própria liberdade, cria a possibilidade do gozo comum desta.

Isso nos permite compreender a paradoxalidade contida na ideia de povo como parte - como tal é nada mais que um humor entre outros humores -, mas animado por um desejo universal: o desejo de liberdade que anima ao povo é desejo de uma parte, mas que se materializa unicamente sob a condição de valer para todos. Seria, porém, um

\footnotetext{
${ }^{18}$ RATMONDI, F. L'ordinamento della libertà. Op. cit. p. 56.

${ }^{19}$ RATMONDI, F. L'ordinamento della libert⿱亠䒑 Op. cit. p., 56.

${ }^{20}$ FROSINI, F. "E questa difficoltà è ragionevole: La perdita della libertà nei 'Discorsi' di Machiavelli". In: PANICH, Nicola. Figure dì 'servitù' e 'dominio' nella cultura filosofica europea tra Cinquecento e Seicento. Florence: Le Lettere, 2010, p. 104.
} 
equívoco imaginar que o povo quer que todos sejam livres e não somente ele. No plano do desejo, ou do humor que lhe é próprio, o povo não se distingue dos grandes em relação à parcialidade de seu desejo. A diferença entre o ato de desejar de povo e o ato de desejar dos grandes não está em que o povo deseja o bem comum ao passo que os grandes apenas o bem próprio. O desejo do povo é desejo de parte do mesmo modo que o dos grandes. A diferença está em que aquilo que a parte popular deseja implica na criação de um ordenamento político (leis e instituições) no qual os grandes não possam prevalecer sem limites sobre o povo. É nesse sentido que a "parcialidade" povo se distingue radicalmente da "parcialidade" grandes. Os grandes, porque movidos pelo desejo de dominar e comandar, são a parte cujo desejo é impossível de tornar-se universal: os grandes realizarão seu desejo de comandar e dominar unicamente sob a condição de que o povo não comande nem domine. É, portanto, um desejo por um bem particular que exclui a outra parte de seu gozo. Já o povo, porque movido pelo desejo de não ser comandado nem oprimido, são a parte cujo desejo é por um bem universal: o povo, resistindo ao desejo de comandar e dominar dos grandes, dá origem a um bem - a liberdade - possível de ser compartilhado por todos.

\section{O processo de corrupção da liberdade}

Por onde entra a corrupção em uma cidade? Na abertura deste trabalho propusemos a hipótese de que a vida livre se corrompe quando o povo dá vazão a dois desejos opostos: ou de excesso ou de falta de liberdade. Conforme a primeira via, a cidade se corrompe quando o povo se deixa arrastar pela ambição e quer governar sozinlho. A segunda via, paradoxalmente, surge quando o povo renuncia ao seu desejo de liberdade e se submete passivamente à dominação dos grandes ou de um príncipe. Nos dois casos - seja pelo excesso ou pela falta - a corrupção se instala por obra do povo: do mesmo modo que a criação de um vivero libero et civile é obra dos tumultos populares, a sua degradação tem igualmente no povo a sua origem. O que pode parecer uma crítica é, na verdade, o reconhecimento da centralidade do povo para a conservação da liberdade republicana. Maquiavel refere isso, por exemplo, quando menciona o processo de corrupção que havia tomado conta dos reis de Roma:

Se a corrupção que havia neles [reis] tivesse começado a espalhar-se pelos membros [povo], se os membros também estivessem corrompidos, teria sido impossível reformá-la [Roma]. Mas, perdida a cabeça quando o busto ainda estava íntegro, os membros poderiam facilmente voltar a viver livres e ordenados ${ }^{21}$. liberdade.

Vamos ocupar-nos agora com a elucidação destes dois caminhos de perda da

\section{A corrupção como resultado do excesso: a luta por ambição}

Maquiavel mostra que a chave do problema da corrupção está na transformação do desejo popular: o desejo de não ser dominado se converte em desejo de dominação, o qual pode ser satisfeito unicamente em detrimento do desejo dos grandes. Recordemos que na base da liberdade está o equilíbrio conflitual entre os desejos opostos de povo e grandes. Os grandes desejam controlar o poder na sua totalidade; o que os impede nisso é a resistência ativa do povo graças à qual surgem leis e ordenações, as quais mantêm sob controle a tendência ao excesso dos grandes. Recordemos também que o desejo popular é "ontologicamente idêntico" (na concepção de Frosini) ao dos grandes. O que o impede a dar vazão a ele é a posição espacial na relação de poder (está na posição "baixa", de ser comandado/governado, ao passo que os grandes estão na posição "alta"

${ }^{21}$ MACHIAVELLI, N. Discorsi sopra la prima Deca di Tío Livio. Op. cit. Livro I, Cap.37, parágrafo 4, p. 139. 
de comandar/governar). Recordemos finalmente que "a natureza criou os homens de tal modo que podem desejar tudo, ainda que não possam obter tudo"22, ou seja, a capacidade de desejar é, por definição, infinita; a natureza humana é destituída de mecanismos internos de controle e, por isso, precisa ser contida externamente. Para Maquiavel, o que limita a tendência natural do desejo humano ao excesso é a necessidade, que pode ser um fenômeno da natureza ou um artifício legal. Quando desaparece a constrição, a corrupção se instala. Maquiavel expressa esta ideia nos seguintes termos: "toda vez que é tolhido aos homens o combater por necessidade, combatem por ambição, a qual é tão poderosa nos peitos humanos que jamais, seja qual for a posição alcançada, os abandona" (grifos nossos) 23.

Esses elementos nos permitem compreender a primeira das duas vias que leva um vivero libero a corromper-se, ou seja, a tendência ao excesso do desejo humano. Além disso, podemos compreender também porque o povo é a força que está na base tanto do surgimento de um vivero libero quanto da sua corrupção: o povo promove a liberdade na medida em que resiste à tendência ao excesso do desejo de comando e opressão dos grandes; e destrói a liberdade na medida em que deseja como os grandes ao querer, tal como estes, comandar e oprimir. Como se comporta o povo nesta situação? A seguinte passagem do começo do Livro I dos Discursos nos dá uma ideia:

Tendo os Tribunos da Plebe essa autoridade Ide guardiã da liberdade republicana】 nas mãos, não lhes bastou um Cônsul plebeu, e quiseram tê-los ambos. A partir daí, quiseram a Censuira, o Pretor e todos os outros cargos do governo da cidade: mas nem isso lhes bastou, pois, levados pelo mesmo furor, começaram depois, com o tempo, a adorar os homens que lhes pareciam aptos a combater a nobreza; donde nasceu o poder de Mário e a ruína de Roma24.

A passagem illustra bem a tendência natural do desejo humano ao excesso e como ele leva à corrupção. Na sua luta contra as pretensões da nobreza de comandar e oprimir, o povo obteve a criação dos Tribunos da Plebe para representar seus interesses e conter o desejo dos grandes. Enquanto o desejo popular ficou restrito a este órgão de representação a liberdade da república permaneceu protegida. Mas assim que surgiu a oportunidade de expandir seu desejo, o povo passou a buscar o controle dos demais mecanismos de governo da cidade. Em lugar de ampliar o espaço da liberdade, o controle pleno do governo pelo povo resultou na ruína dela.

A mesma dinâmica é referida por Maquiavel mais adiante quando menciona o exemplo dos Gracos:

Disse isso, porque à plebe romana não bastou assegurar-se em relação aos nobres com a instituição dos Tribunos, desejo ao qual foi forçada pela necessidade; pois ela, tão logo obteve essa lei, começou a combater por ambição e a querer dividir cargos e patrimônio com a nobreza, como coisa mais valiosa para os homens. Daí surgiu a doença que gerou o litígio da lei agrária, que acabou por ser a causa da destruição da república (grifos nossos) ${ }^{25}$.

Também aqui Maquiavel aponta diretamente à raiz do problema: a corrupção se instala quando o desejo não encontra limites, ou constrição, ao livre curso dele. Mostra igualmente que a corrupção tem sua origem na desmesura do desejo popular, pois o povo deixa de ser rival dos grandes para ser como os grandes. Nesta situação, passa a compartilhar com eles o desejo pelos mesmos bens (honras e riquezas) e a desejar, tal como eles, exercer o poder como sua finalidade última. Não mais contido pela necessidade, "começa a combater por ambição" e esta "é tão poderosa no coração dos hhomens que jamais, seja qual for a posição alcançada, os abandona"; como consequência

${ }^{22}$ MACHIAVELLI, N. Discorsi sopra la prima Deca di Tito Livio. Op. cit. Livro I, Cap. 4, parágrafo 7, p. 71.

${ }^{23}$ MACHIAVELLI, N. Discorsi sopra la prima Deca di Tito Livio. Op. cit. Livro I, Cap. 37, parágrafo 3, p. 139.

${ }^{24}$ MACHIAVELLI, N. Discorsi sopra la prima Deca di Tito Livio Op. cit. Livro I, Cap. 5, parágrafos 10-11, p. 73.

${ }_{25}$ MACHIAVELLI, N. Discorsi sopra la prima Deca di Tito Livio. Op. cit. Livro I, Cap. 37, parágrafos 6-7, p. 140. 
disso, temos "a destruição da república"26.

\section{A corrupção como resultado da ausência do desejo de liberdade: a submissão passiva}

Essa segunda porta de entrada da corrupção em uma cidade nos defronta com uma situação paradoxal. Com efeito, no capítulo IX de O Príncipe Maquiavel caracteriza o humor do povo como animado pelo desejo de "não ser comandado nem oprimido pelos grandes"27, em outros termos, o povo é movido pelo desejo ativo de liberdade. O que define a condição do povo, conforme esta passagem do Príncipe, é a luta pela liberdade, ainda que vivida negativamente como resistência à pretensão dos grandes de comandálo e oprimi-lo. A situação que Maquiavel pretende analisar agora é aquela na qual um povo, "habituado a viver sob um príncipe", está "habituado a obedecer" e, por conseguinte, "não sabe viver livremente"28. Podemos notar que se trata de uma condição aparentemente inconciliável com a doutrina dos humores, pois esta atribui ao povo o desejo ativo de não ser comandado e de viver livre da opressão.

Nos capítulos XVI a XVIII do Livro I dos Discursos Maquiavel tematiza precisamente o quadro de um povo que, "acostumado a obedecer [...], não sabe viver livremente" quando, eventualmente, recobra a liberdade. A dificuldade de conservar a liberdade para um povo "acostumado a viver sob a autoridade de um príncipe", quando se liberta de seu jugo, pode ser comparada, afirma Maquiavel, à dificuldade de um animal criado em cativeiro quando é devolvido à natureza:

Esse povo não é de outro modo que uim animal bruto que, embora de natureza feroz e silvestre, tenha sido criado sempre no cativeiro e na servidão, e que depois, deixado livre em campo aberto, por não estar acostumado a alimentar-se e por não conhecer os lugares onde possa refugiar-se, torna-se presa do primeiro que queirra aprisioná-lo de novo ${ }^{29}$.

A liberdade não é alguma coisa inerente à natureza humana. Ela é resultado do "costume" (uso/abitudine). Por isso, quando um povo é deixado livre da submissão a um príncipe ele não sabe usufruir as vantagens da vida livre, e "rapidamente retorna sob um jugo, que na maioria das vezes é mais pesado do que o anterior ${ }^{\prime 30}$.

O costume se converte, dessa maneira, em uma espécie de "segunda natureza", um modo de ser que determina o curso da ação de um povo como se fosse uma força regida pela necessidade; isso é verdadeiro tanto para a conservação da liberdade quanto para a submissão ao jugo tirânico (perda da liberdade). O costume aparece, desse modo, como o depositário da inércia coletiva, do consentimento irrefletido: o povo acaba se comportando como "um animal bruto", escreve Maquiavel. Uma vez que a liberdade é resultado de um hábito, um povo acostumado à liberdade é praticamente impossível de ser subjugado, de sorte que, "quem se torna senhor de uma cidade acostumada a viver livre e não a destrói, pode esperar ser destruído por ela" (grifos nossos) ${ }^{31}$. De outro lado, porém, ưm povo acostumado à servidão, ainda que se liberte do jugo, não "sabe" viver livremente de modo que passa das mãos de um príncipe às de outro. Este povo, como Maquiavel escreve em Discursos ( $\mathrm{I}, 16: 23$ ), não quer a liberdade como participação, mas como gozo passivo de uma condição na qual a segurança de cada um é garantida pela lei.

No capítulo XVII do Livro I dos Discursos Maquilavel acrescenta um dado novo, e perturbador, da sulbmissão de um povo. Não se trata da servidão na qual um povo perde a liberdade como resultado da opressão tirânica exercida por um príncipe. Quando se configura semelhante quadro, o desejo de liberdade ainda continua vivo; ele apenas está

\footnotetext{
${ }^{26}$ MACHIAVELLI, N. Discorsi sopra la prima Deca di Tito Livio. Op. cit. Livro I, Cap. 37, parágrafo 3, p. 139.

${ }^{27}$ MAQUIAVEL, N. O Príncipe Op. cit. Cap. IX, parágrafo 2, p. 109.

${ }^{28}$ MAQUIAVEL, N. O Príncipe Op. cit. Cap. V, parágrafo 8, p. 67.

${ }^{29}$ MACHIAVELLI N. Discorsi sopra la prima Deca di Tito Livio. Op. cit. Livro I, Cap. 16, parágrafo 4, p. 103

${ }^{30}$ MACHIAVELLI, N. Discorsi sopra la prima Deca di Tito Livio. Op. cit. Livro I, Cap. 16, parágrafo 4, p. 103.

${ }^{31}$ MAQUIAVEL, N. O Príncipe Op. cit. Cap. V, parágrafo 6, p. 65.
} 
sufocado e basta aparecer um momento oportuno para tomar corpo e retomar a vida livre. O que Maquiavel reflete nos capítulos citados é a situação na qual o desejo mesmo de liberdade enquanto tal está ausente! É a condição daquele povo que se acostumou à servidão; ou seja, ela considera a servidão algo "natural"! Semelhante povo, vimos acima, mesmo quando eventualmente recobra a liberdade, não é capaz de conservá-la e rapidamente cai novamente sob o jugo de outro tirano. Trata-se, portanto, escreve Maquiavel, do giogo che da se medesima si metteva in sul collo: "do jugo que a si mesmo colocou no pescoço"32. É, pois, "uma sujeição que não se nutre do medo, mas tem uma trama mais sutill, mais subliminar: uma dominação que constrói o próprio consentimento"33. Aqui, parece, Maquiavel pretende levar-nos a refletir a situação na qual um povo, "iludido por uma falsa imagem de bem", promove a transformação de seu desejo de liberdade em um "desejo da própria ruína"34. Trata-se, pois, de uma "passivização" do desejo popular no qual prevalece unicamente a monodirecionalidade de príncipe-súditos voltado à adaptação a servir.

Em suma, a reflexão de Maquiavel nos alerta de que o desejo de liberdade está sempre exposto ao risco de converter-se em seu oposto, seja quando a resistência ao desejo dos grandes desanda em ambição, seja quando o desejo se converte em aceitação passiva do jugo tirânico como se fosse liberdade. Aqui nos parecem oportunas as palavras de Visentin proferidas no curso ministrado durante o XXI Simpósio de Filosofia da Unioeste: "A liberdade do povo se manifesta, assim, como una forma de resistência, tanto em relação às tentativas de dominação provenientes de fora, quanto em relação ao risco implícito no desejo de liberdade de produzir efeitos que o transformam de tempos em tempos em anseio de domínio, ou em vontade de servir".

\section{As alternativas para a restauração da liberdade}

Seja porque o desejo de liberdade desanda em ambição, seja porque o desejo de liberdade se apaga: nas duas situações a vida política se degrada a ponto de corromper por inteiro o vivero libero. Neste quadro, como devolver um povo a uma vida livre? Nos capítulos XVI a XVIII do Livro I dos Discursos Maquiavel examina as diferentes possibilidades. Dadas as limitações de espaço, nos limitaremos a apontar resumidamente os três diferentes caminhos indicados por Maquiavel nos capítulos mencionados.

\section{Como instaurar uma vida livre quando um povo, acostumado ao jugo de um príncipe, se liberta (capítulo XVI)}

O primeiro quadro que Maquiavel submete à análise é o da "grande dificuldade que um povo acostumado a viver sob a autoridade de um príncipe enfrenta para conservar a liberdade que por algum acontecimento venha a conquistar" ${ }^{* 35}$. Trata-se da situação comentada anteriormente, na qual um povo se assemelha a "um animal bruto [...] mantido sempre em cárcere e em servidão"36. Quando este povo readquire a liberdade, faltando-lhe o hábito do autogoverno e o conhecimento que isso requer, rapidamente retorna ao jugo de outro príncipe.

A solução de semelhante quadro se defronta com a seguinte dificuldade: "o estado que se torna livre angaria partidários inimigos e não partidários amigos" 37. Quando se muda de regime - de principado a repúlblica, por exemplo - tornam-se inimigos "todos aqueles que no estado tirânico se prevaleciam cevando-se das riquezas

32 MACHIAvELLI, N. Discorsi sopra la prima Deca di Tito Livio. Op. cit. Livro I, Cap. 17, parágrafo, p. 108.

33 Comentário de Stefano Visentin em curso ministrado no XXI Simpósio de Filosofia Moderna e Contemporânea da Unioeste.

34 MACHIAVELLI, N. Discorsi sopra la prima Deca di Tito Livio. Op. cit. Livro I, Cap. 53, parágrafo 6 , p. 169.

35 MACHIIVELLI, N. Discorsi sopra la prima Deca di Tito Livio Op. cit. Livro I, Cap. 16, parágrafo 2 , p. 103.

${ }^{36}$ MACHIAVELLI, N. Discorsi sopra la prima Deca di Tito Livio. Op. cit. Livro I, Cap. 16, parágrafo 3, p. 103.

${ }^{37}$ MACHIIVELLI, N. Discorsi sopra la prina Deca di Tito Livio. Op. cit. Livro I, Cap. 16, parágrafo 6, p. 103. 
do príncipe"38. Além disso, na república "não se conquistam partidários amigos, porque na vida livre concedem-se honrarias e prêmios por algumas razões honestas e determinadas, afora as quais não se premia nem se honra ninguém"39. Para superar essas dificuldades, parecem existir dois caminhos: ou "matar os fillhos de Brutos" matar os herdeiros daqueles gozavam de posições de privilégio no regime anterior - ou fazer amigos com seus inimigos em vez de matá-los. O inconveniente do primeiro caminho é que "aqueles que, para assegurar seu estado, precisam valer-se de meios extraordinários [...] têm por inimigo a multidão [...] e jamais estarão seguros, pois quanto mais crueldade usarem, mais fracos se tornarăo"41. O único caminho viável, portanto, parece ser o segundo: "procurar angariar a amizade do povo"42. O povo, escreve Maquiavel, "sempre deseja duas coisas: uma é vingar-se dos que lhe acarretam a servidão, e outra é recobrar a liberdade" ${ }^{m 43}$. Para satisfazer o primeiro desejo basta imitar Clearco, tirano de Heracléa, o qual "aniquilou todos os optimates, para extrema satisfação do povo"44. O segundo desejo, embora mais complicado, é possível de ser satisfeito, pois apenas "uma pequena parte deseja ser livre para comandar, mas todos os outros [...] desejam a liberdade para viverem seguros" ${ }^{\prime \prime 4}$.

\section{Como tornar livre uma cidade corrompida quando morre seu príncipe (capítulo XVII)}

A questão que Maquiavel se propõe no capítulo XVII é a de saber se, e como, é possível restaurar a liberdade de uma cidade depois de morto o príncipe com toda a sua estirpe. Para começar, Maquiavel pondera que, se a corrupção atinge os chefes ou se ela se difunde pelos membros, readquirir a liberdade não é suficiente, porque não saberiam como conservá-la voltando a ser uma cidade corrompida. Ao invés disso, "onde a matéria não é corrupta, os tumultos e os outros escândalos não causam danos" ${ }^{\prime \prime}$. Na situação contrária, em que "uma cidade entrou em decadência por corrupção da matéria, se porventura for soerguida só poderá sê-lo pela virtù de um homem que então esteja vivo e não pela virtù do povo"47. Contudo, basta este homem morrer para retornar ao anterior estado de corrupção, pois sua virtù não se transmitirá uma vez que não existe hereditariedade da virtù pessoal.

Em suma, Maquiavel parece entender, pelo dito nestes dois capítulos (XVI e XVII) que, para um povo viver livre, deve estar acostumado à liberdade e não inteiramente corrompido, isto é, submetido servillmente a um tirano. Como vimos, a liberdade é um valor internalizado pelo costume. Para restabelecê-la ali onde entrou em decadência é necessário que ainda não tenlha tomado conta do inteiro corpo político. Outro aspecto ao qual Maquiavel chama a atenção é o de quie a figura do príncipe (ou a dos chefes sob uma república) é irrelevante em relação a este processo. Com efeito, se for o caso de um tirano (como no capítulo XVI), ele deixa o povo, mesmo que não esteja corrompido, incapacitado de ser livre; se for um príncipe virtuoso (como no capítullo XVII), ele será incapaz de transmitir-lhe a própria virtù, deixando o povo igualmente impossibilitado de ser livre.

\section{Como proceder para fazer retornar à liberdade uma cidade tomada inteiramente pela corrupção (capítulo XVIII)}

\footnotetext{
${ }^{38}$ MACHIAVELLI, N. Discorsi sopra la prima Deca di Tito Livio. Op. cit. Livro I, Cap. 16, parágrafo 7, p. 103.

${ }^{39}$ MACHIAVELLI, N. Discorsi sopra la prima Deca di Tito Livio. Op. cit. Livro I, Cap. 16, parágrafo 8, p. 103.

${ }^{40}$ MACHIAVELLI, N. Discorsi sopra la prima Deca di Tito Livio. Op. cit. Livro I, Cap. 16, parágrafo 11, p. 104.

${ }^{41}$ MACHIAVELLI, N. Discorsi sopra la prima Deca di Tito Livio. Op. cit. Livro I, Cap. 16, parágrafo 13, p. 104.

${ }^{42}$ MACHIAVELLI, N. Discorsi sopra la prima Deca di Tito Livio. Op. cit. Livro I, Cap. 16, parágrafo 14, p. 104.

${ }^{43}$ MACHIAVELLI, N. Discorsi sopra la prima Deca di Tito Livio. Op. cit. Livro I, Cap. 16, parágrafo 16, p. 104.

${ }^{44}$ MACHIAVELLI, N. Discorsi sopra la prima Deca di Tito Livio. Op. cit. Livro I, Cap. 16, parágrafo 21, p. 105.

${ }^{45}$ MACHAVELLI, N. Discorsi sopra la prima Deca di Tito Livio. Op. cit. Livro I, Cap. 16, parágrafo 23, p. 105.

${ }^{46}$ MACHIAVELLI, N. Discorsi sopra la prima Deca di Tito Livio. Op. cit. Livro I, Cap. 17, parágrafo 13, p. 107.

${ }^{47}$ MACHIAVELLI, N. Discorsi sopra la prima Deca di Tito Livio. Op. cit. Livro I, Cap. 17, parágrafo 13, p. 107.
} 
O problema que Maquiavel pretende discutir neste capítulo é, segundo suas palavras, "considerar se numa cidade corrompida é possível manter o estado livre caso

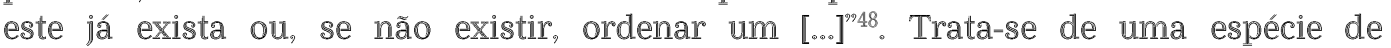
"experimento mental". Para tanto, escreve Maquiavel, "pressuporei uma cidade extremamente corrompida [...] onde não há leis nem ordenações que bastem para frear uma corrupção generalizada" (grifos nossos) ${ }^{49}$. Para examinar este ponto, Maquiavel aponta primeiro para a recursividade de leis e costumes e depois para a recursividade de leis e ordenações.

A recursividade de leis e costumes se mostra no fato de, em semelhante cidade (corrompida), as leis serem ineficazes, pois "para serem observadas têm necessidade de bons costumes" e estes estarão ausentes, "porque para manter-se têm necessidade das leis" ${ }^{\prime \prime 50}$. Leis e costumes, isoladamente, são incapazes de frear a corrupção. Os costumes precisam ser bons para que as leis sejam respeitadas. Por outro lado, as leis se tornam boas unicamente se elas promovem os bons costumes. Por mais corrupta que uma cidade esteja, sua existência implica um mínimo de bons costumes que garantam o mínimo de respeito às leis.

Em seguida, Maquiavel aponta para a recursividade entre leis e ordenações: "se as leis de uma cidade variam segundo os acontecimentos, suas ordenações nunca ou raramente variam: isso faz com que as novas leis não bastem, porque as ordenações, que estão firmes, as corrompem" "51. A causa da corrupção não está nas leis, mas nas ordenações, pois ao não acompanhar a variação dos acontecimentos, impedem a regeneração da virtù. Assim, a imutabilidade das ordenações da cidade gera os maus costumes que impedem às leis manter os homens bons. Consequentemente, para que uma cidade "se manten ha livre naquele estado de corrupção", é necessário que crie não somente "novas leis", mas igualmente "novas ordenações"52. Isto leva Maquiavel a propor duas alternativas hipotéticas, "ambas quase impossíveis"53.

A primeira alternativa é a mudança gradual ou rinnovazione. A condição de êxito desta alternativa é que "seja promovido por um homem prudente que perceba o inconveniente de antemão, quando nasce" ${ }^{" 54}$. A dificuldade de semelhante alternativa está não apenas na raridade de existir um homem desse feitio, como também o fato de, vendo os perigos antes dos demais, ter de ser capaz de convencer seus concidadãos a mudar as ordenações antes que eles se próprios se dêem conta do perigo. Ora, pondera Maquiavel, quem está "acostumado a viver de um modo" a só reconhecer o perigo quando este é patente, reluta diante da necessidade de mudança. Assim, mesmo que apareça um homem de tamanha virtù "que perceba o inconveniente de antemão", nada poderá fazer no sentido de reformar as ordenações.

A segunda alternativa é a transformação radical ou innovazione. A condição de êxito desta alternativa implica em aceitar recorrer a um príncipe capaz de servir-se dos "modos extraordinários, como a violência e as armas, tornando-se, antes de mais nada, príncipe em tal cidade para dispô-la a seu modo"s5. Ora, pondera Maquiavel, esta alternativa se defronta com o seguinte paradoxo: para fazer voltar uma cidade ao vivere libero se faz necessário um homem bom e para ser príncipe é preciso um homem mau capaz de servir-se dos meios extraordinários; seria preciso, pois, existir um homem que fosse, ao mesmo tempo, bom e mau. Mesmo sendo bom, deveria pelos meios maus tornar-se príncipe e passar a agir bem renunciando aos meios extraordinários em favor dos ordinários governando por meio das novas ordenações instituídas através da violência e das armas. Nasce disso, continua Maquiavel, "a dificuldade, ou

${ }^{48}$ MACHIAVELLI, N. Discorsi sopra la prima Deca di Tito Livio. Op. cit. Livro I, Cap. 18, parágrafo 2, p. 108.

${ }^{49}$ MACHIAVELLI, N. Discorsi sopra la prima Deca di Tito Livio. Op. cit. Livro I, Cap. 18, parágrafo 4, p. 108-109.

${ }^{50}$ MACHIAVELLI, N. Discorsi sopra la prima Deca di Tito Livio. Op. cit. Livro I, Cap. 18, parágrafo 5, p. 109.

${ }^{51}$ MACHIAVELLI, N. Discorsi sopra la prima Deca di Tito Livio. Op. cit. Livro I, Cap. 18, parágrafo 7, p. 109.

${ }^{52}$ MACHIAVELLI, N. Discorsi sopra la prima Deca di Tito Livio. Op. cit. Livro I, Cap. 18, parágrafo 22, p. 110.

${ }^{53}$ MACHIAVELLI, N. Discorsi sopra la prima Deca di Tito Livio. Op. cit. Livro I, Cap. 18, parágrafo 23, p. 110.

${ }^{54}$ MACHIAVELLI, N. Discorsi sopra la prima Deca di Tito Livio. Op. cit. Livro I, Cap. 18, parágrafo 24, p. 110.

55 MACHIAVELLI, N. Discorsi sopra la prima Deca di Tito Livio. Op. cit. Livro I, Cap. 18, parágrafo 26, p. 111. 
impossibilidade, de, nas cidades corrompidas, manter ou criar uma república" ${ }^{n 56}$. o caminho que resta, no entendimento de Maquiavel, seria o de "reduzi-la [a cidade] mais ao estado régio que ao estado popular para que os homens, cuja insolência não possa ser corrigida pelas leis, fossem de algum modo freados por uma autoridade quase régia"57. Significa dizer: para reordenar uma república seria necessário primeiro transformá-la em principado para que depois que "a autoridade quase régia" tivesse domado os insolentes fosse transformada novamente em república.

\section{Considerações finais}

Em suma, para Maquiavel a liberdade não é uma qualidade inerente à condição humana, como será entendida nas teorias do contrato modernas para as quais ela se constitui num "direito natural" inalienável do indivíduo. Ao invés disso, para Maquiavel a liberdade é sempre uma prática, um produto da ação e, consequentemente, é uma obra coletiva. Para ele a liberdade não é algo abstrato, mas situado, algo que acontece pela luta coletiva dos homens em contextos históricos concretos. Por esta razão, jamais está dada de modo definitivo. O modo melhor de conservá-la é através de uma constituição mista, ou seja, aquela na qual os diferentes humores da cidade estão misturados. Esse é o motivo pelo qual Maquiavel elogia os tumultos, pois somente por meio deles é possível misturar os humores da cidade. Assim, paradoxalmente, os tumultos são, ao mesmo tempo, aquilo que põe em risco a vida livre da cidade e a única coisa capaz de produzi-la. Uma vez que a liberdade é um produto histórico (ou "artificial") alcançado por meio da luta, do confronto com os grandes, está sempre exposta à sua perda, à corrupção.

Maquiavel, a propósito, aponta para os dois modos de perder a liberdade: quando desaparece a constrição resultante da necessidade e os homens passam a lutar por ambição, temos o excesso, a desmesura; quando há renúncia e capitulação a um dos humores da cidade, o dos grandes/príncipe, e os homens se submetem passivamente ao jugo, temos a falta. Nas duas situações se mostra a importância do costume: por um lado, quando um povo está habituado à liberdade é praticamente impossível submetê-lo ao jugo; por outro lado, quando um povo está habituado ao jugo é praticamente impossível fazê-lo viver livremente. Por isso, pondera Maquiavel, é "quase impossível" restaurar a liberdade ali onde o corpo político está inteiramente corrompido, pois para isso seria necessária uma "mão régia" que pudesse servir-se da força e violência que, no entanto, tende a converter-se em tirania.

Enfim, a liberdade para Maquiavel é resultado da luta entre os humores opostos que agitam as cidades na medida em que produzem leis e instituições que, por um lado, impedem que os grandes prevaleçam e, por outro, asseguram ao povo espaços de participação nas estruturas de governo.

\section{Referências}

BARBERIS, M. Libertà. Bologna: Il Mulino, 1999.

DEJARDIN, Bertrand. Terreur et corruption.Essai sur l'incivilité chez Machiavel. Paris: L'Harmattan, 2004.

FROSINI, F. "E questa difficoltà è ragionevole: La perdita della libertà nei 'Discorsi' di Machiavelli". In: PANICHI, Nicola. Figure di 'servitù' e 'dominio' nella cultura filosofica europea tra Cinquecento e Seicento. Florence: Le Lettere, 2010.

GEUNA, Marco. Machiavelli e il ruolo dei conflitti nella vita politica. In VV.AA. Conflitti (a cura di A. Arienzo, D. Caruso). Napoli: Dante\&Descartes, 2005, pp. 19-57.

\footnotetext{
${ }^{56}$ MACHIAVELLI, N. Discorsi sopra la prima Deca di Tito Livio. Op. cit. Livro I, Cap. 18, parágrafo 28, p. 111.

${ }^{57}$ MACHIAVELLI, N. Discorsi sopra la prima Deca di Tito Livio. Op. cit. Livro I, Cap. 18, parágrafo 29, p. 111. 
ILLUMINATI, Augusto e RISPOLI, Tania. Tumulti. Scene dal nuovo disordine planetario. Roma: Derive Approdi, 2011,

LEFORT, C. Le Travail de l'œuvre Machiavel. Paris: Éditions Gallimard, 1972.

MACHIAVELLI, N. Discorsi sopra la prima Deca di Tito Livio. Introdução de Gennaro Sasso; preâmbulo e notas de Giorgio Inglese. Milano: Rizzoli Editore, 2000.

MAQUIAVEL, N. O Príncipe (edição bilíngue). Tradução e notas de José Antônio Martins. São Paulo: Hedra, 2009.

RAIMONDI, F. L'ordinamento della libertà: Machiavelli e Firenze. Verona: Ombre Corte, 2013.

VISENTIN, S. Liberdade e servidão na primeira modernidade: Machiavelli, La Boétie, Hobbes, Spinoza. Curso ministrado durante o XXI Simpósio de Filosofia Moderna e Contemporânea da Unioeste de 7 a 11 de novembro de 2016.

Doutor em Filosofia (UNICAMP, 2000)

Professor do PPG Filosofia/UNIOESTE

Email: jluizames@gmail.com 